\title{
Effectiveness Analysis of Emission Reduction Measures in the Huangshui River Watershed Based on MIKE11 Model
}

\section{ZHENG Xiaokang ${ }^{1, ~ a, ~ P E N G ~ S h a o m i n g ~}{ }^{1, b}$, YANG Hang ${ }^{2, c}$, and ZHAO Xinlei ${ }^{1, d}$}

\author{
${ }^{1}$ Yellow River Engineering Consulting Co., Ltd. No.109 Jinshui Road, Zhengzhou ,China \\ ${ }^{2}$ Hydrology and Water Resources Institute, Hohai University, No.1 Xikang Road, Nanjing ,China \\ azhengxk@yrec.cn, bpengshming@163.com, c1140335776@qq.com, d137087645@qq.com
}

Keywords: MIKE11, Huangshui River, water quality model, emission reduction measures, effectiveness analysis

Abstract: To analyze the effectiveness of pollutant cap control mode towards pollutant reduction and the improvement of water quality in the section, this paper took the Huangshui River Watershed as an example, with main pollutants $\mathrm{COD}$ and $\mathrm{NH}_{3}-\mathrm{N}$ as the main indicators. And established a water quality model based on MIKE11in Xining downstream. By calibration and verification, the model proves to have high precision, adaptability and reliability. Combining situational analysis methods to quantify the effectiveness of the two control methods, regular emission mode and pollutant cap control mode, the results show that pollutant cap control mode has a better effect on emission reduction than regular emission mode. Under this discharge method, the COD and $\mathrm{NH}_{3}-\mathrm{N}_{\text {of }}$ all sections in Xining downstream can reach Grade IV water quality standards for surface water environment, and meet the water quality objectives of water functional areas, pollutant cap control mode is the key measures to improve river water quality. The research results can provide technical support for water pollution prevention and water environment management and planning in the Huangshui River Watershed, and can also provide reference for relevant engineering decision-making of river regulation.

\section{Introduction}

Water pollution is known as one of major environmental issues in the world and water quality management become an essential task in integrated river watershed management (Kotti et al. 2005). The main objective of water quality simulation is to quantitatively describe the pattern of temporal and spatial evolution of river water quality, and to provide technical support for the prevention and treatment of river water pollution. At present, QUAL2K, WASP, MIKE and other models are widely used, They are mostly used in the simulation and prediction of pollution accident (Wang et al., 2008), water quality prediction (Lin et al., 2012; Jin et al., 2010) and water volume scheduling (Arega et al., 2003) and other research areas. Among them, the MIKE series model has high precision and versatility, and in the revised version of the current guideline for water environment impact assessment, the MIKE software is also proposed as one of the guide recommendation software. Chinese scholars have also conducted extensive research on the application of MIKE 11 in river water bodies, It has been successfully applied in fields such as simulation of changes in hydrodynamics before and after dam construction, simulation of migration and diffusion of pollutants in sudden water pollution accidents, simulation of water quality and forecasting (Xiong et al., 2017).

This article used the MIKE11 model as a tool, and established a simulation model of water quality and quantity for the reaches below Xining in Huangshui River. Combining situational analysis methods to quantify the effectiveness of the two control methods, regular emission mode and pollutant cap control mode, it provides a new technical method for assessing the effectiveness of pollutant reduction measures. 


\section{Study area}

Huangshui is a primary tributary of the Yellow River. It originates from the south of Daban Mountain in Haiyan County, Qinghai Province. It flows through the 12 counties (districts) of Qinghai and Gansu Provinces from west to east, and into the Yellow River at Shangche Village in Yongjing County. The total length is $374 \mathrm{~km}$, and the drainage area is $17733 \mathrm{~km}^{2}$.

In recent years, with the increase of population in the Huangshui River watershed and the rapid development of the social economy, the water pollution control in the river watershed lags behind, and the water pollution situation has become severe, which caused serious impact on the production and domestic water consumption in the city. According to the data of water quality monitoring in 2015, the annual water quality of the major sections below Xining, is basically in the inferior category, and the main factors that exceed standard are COD and $\mathrm{NH}_{3}-\mathrm{N}$. The sources of pollution are mainly industrial, urban life, rural life, agricultural non-point source pollution, Among them, the point source pollution of industrial wastewater and urban domestic sewage along the river is relatively serious .It has become the main reason for the excessive water quality in all sections of Huangshui.

The following sections of the river below Xining in Huangshui involve the two most developed and most densely populated areas, namely the Xining and Haidong regions of Qinghai Province. About $50 \%$ of the population and about $60 \%$ of GDP of Qinghai Province are concentrated in these areas. It is also the most prominent section of the river in terms of water pollution. Therefore, this study selected the reaches below Xining in Huangshui, and analyzed the effectiveness of the pollutant cap control mode for pollutant reduction and improvement of section water quality, in order to provide technical support for water pollution control in the Huangshui watershed.

\section{Model construction and parameter identified}

\section{Introduction of MIKE11 Model}

MIKE11 is a one-dimensional hydraulic and water quality model developed by the Danish Institute of Water and Water Environment (DHI) and can operating on the windows platform. It includes three modules: hydrodynamics, advection-diffusion and water quality, which can be used for simple and complex rivers. Water quality and water quality system simulation analysis, design and forecasting provide comprehensive methods and strong technical support for river water environment simulation (DHI, 2007). Currently, MIKE 11 has been validated by applications and has become a standardized tool for water quality simulation in many countries. The model frame of MIKE11 consists of the HD Module and the AD Module.

The hydrodynamics module is based on the one-dimensional Saint-Venant equation. The simulation results are hydrological factors such as water levels and flow rates at various sections and times of the river, the expression is as follows:

$$
\left\{\begin{array}{l}
\frac{\partial \mathrm{A}}{\partial \mathrm{t}}+\frac{\partial Q}{\partial \mathrm{x}}=\mathrm{q} \\
\frac{\partial Q}{\partial \mathrm{t}}+\frac{\partial}{\partial \mathrm{x}}\left(\frac{\mathrm{Q}^{2}}{\mathrm{~A}}\right)+\mathrm{gA} \frac{\partial \mathrm{h}}{\partial \mathrm{x}}+\mathrm{g} \frac{\mathrm{Q}|\mathrm{Q}|}{\mathrm{C}^{2} \mathrm{AR}}=0
\end{array}\right.
$$

in which, $x$ is the distance coordinate; $t$ is the time coordinate; $A$ is the cross-section area; $Q$ is the flow; $q$ is the side inflow; $h$ is the water level; $R$ is the hydraulic radius; $g$ is the acceleration of gravity; $C$ is the coefficient of Chezy.

The basic equation of a one-dimensional river water quality model is the one-dimensional convection diffusion equation. The equation assumes that the material is conserved and all mixed on the cross section or that it conforms to first-order reaction kinetics and Fick's law of diffusion, that is, the diffusion is proportional to the concentration gradient.

$$
\frac{\partial A C}{\partial t}+\frac{\partial Q C}{\partial x}-\frac{\partial}{\partial x}\left(A D \frac{\partial C}{\partial x}\right)=-A K C+C_{2} q
$$


In which, $x, t$ are space coordinates $(\mathrm{m})$ and time coordinates $(\mathrm{s}) ; C$ is the concentration of matter $(\mathrm{mg} / \mathrm{L}) ; D$ is the longitudinal expansion coefficient $\left(\mathrm{m}^{2} / \mathrm{s}\right) ; A$ is the cross-sectional area $\left(\mathrm{m}^{2}\right) ; C_{2}$ is the source sink concentration $(\mathrm{mg} / \mathrm{L}) ; K$ is the linear attenuation coefficient $\left(\mathrm{d}^{-1}\right)$.

\section{Model construction}

Based on the water system file generated by ArcGIS in shape format, a river network file for the main stream of the Huangshui River in Mike11 was created, andinformation of the river's long coordinates and length was confirmed. Adopting measured data of large sections such as Xining, Ledu, Minhe and the others as the input data for cross-section files, the required section input file was generated through automatic interpolation. The Xining section of the Huangshui River was taken as the input, and the entry of the Huangshui River into the Yellow River as the output, the flow rate, the water level boundary, the tributaries of the middle reaches of the river, inlets, outlets and the other boundary conditions were set respectively ..

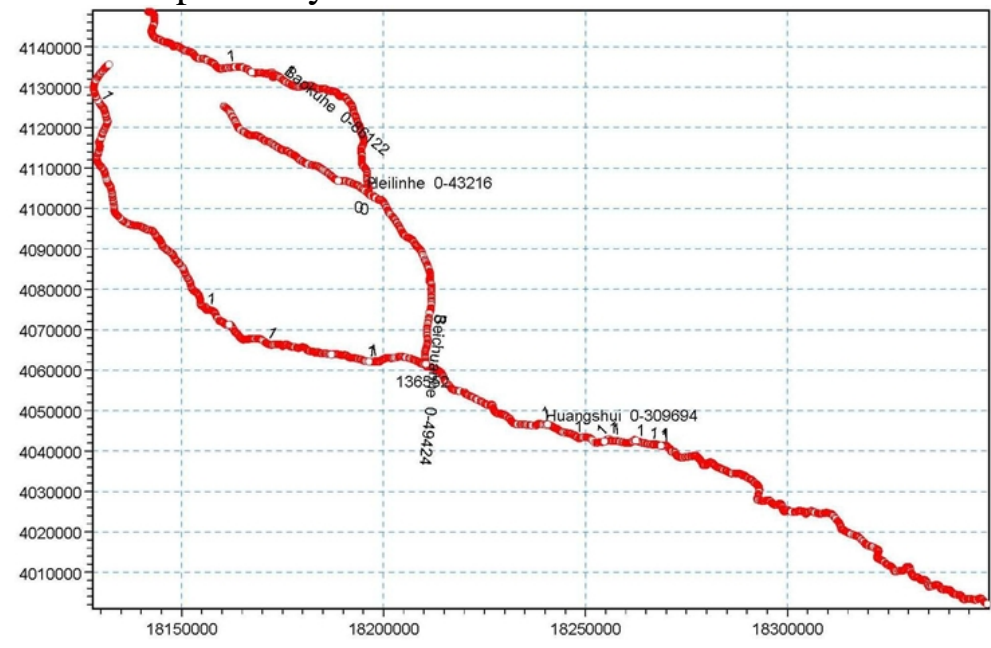

Figure 1 : River Network File Schematic in Huangshui River Basin

\section{Model calibration and verification}

\section{Calibration method}

Intake survey, sewage survey, and measured large-section of the main stream of Huangshui in 2013 were used data as model input. The daily water quantity and water quality data from January to August were substituted into the model to fit the model parameters and to caliberate the main parameters of the model. In order to further verify the precision, applicability and reliability of the model, and the boundary of the input calculation model, the calibrated model parameters ,then the model was verified by daily measured data from September to December were adopted to verify the model. The criteria for model parameters caliberation includes: 1) Simulated and measured error should be as small as possible. 2) Nash-Sutcliffe efficiency should be as large as possible. 3) The correlation coefficient between simulated value and measured value should be as large as possible.

In the process of formulating initial parameters, we simulated the flow and pollution concentration of hydrology and water quality monitoring stations in the main stream of Huangshui River under MIKE11 model's boundary conditions. We compared simulated and observed value by parameters initialization, trimming, fitting, re-trimming, re-fitting and other methods until the simulated value converged. If it's fitted to calibration criteria, then we could set down the model's parameters.

Table 1. Model parameter settings

\begin{tabular}{ccccc}
\hline \multirow{2}{*}{ Section } & \multirow{2}{*}{ Bed roughness } & $\begin{array}{c}\text { Diffusion coefficient } \\
\left(\mathrm{m}^{2} / \mathrm{s}\right)\end{array}$ & \multicolumn{2}{c}{ Attenuation coefficient } \\
\cline { 4 - 5 } & & 6.0 & $\mathrm{COD}$ & \\
\hline Xining-Xiaoxiaqiao & 0.040 & 6.0 & 0.3 & 0.25 \\
\hline Xiaoxiaqiao-Pinganqiao & 0.036 & 7.5 & 0.4 & 0.35 \\
\hline Pinganqiao-Ledu & 0.043 & 8.5 & 0.3 & 0.35 \\
\hline Ledu-Minhe & 0.045 & 8.5 & 0.3 & 0.25 \\
\hline The following of Minhe & $0.045 \mathrm{c}$ & & & \\
\hline
\end{tabular}




\section{Calibration results}

1) water quantity model .

The simulated results show that the projected average errors of three main sections are all less than $20 \%$, the Nash efficiency indexes of each section's projected water volume are $0.82,0.63$ and 0.98 , the relative coefficient are $0.9,0.78$ and 0.99 . The parameters calibration errors, Nash efficiency index and relative coefficient of the flow projection of the main sections of Ledu, Minhe and Honggu are shown in Table.2.

Table 2. Results of runoff of main hydrological stations conditioned by parameters of water model

\begin{tabular}{|c|c|c|c|c|c|c|c|}
\hline \multirow[b]{2}{*}{ Section } & \multicolumn{2}{|c|}{$\begin{array}{l}\text { Traffic characteristics } \\
\qquad\left(\mathrm{m}^{3} / \mathrm{s}\right)\end{array}$} & \multicolumn{3}{|c|}{$\begin{array}{l}\text { Rate deviation } \\
(\%)\end{array}$} & \multirow{2}{*}{$\begin{array}{l}\text { Nash efficiency } \\
\text { coefficient }\end{array}$} & \multirow{2}{*}{$\begin{array}{l}\text { Correlation } \\
\text { coefficient }\end{array}$} \\
\hline & $\begin{array}{l}\text { Measured } \\
\text { Flow }\end{array}$ & $\begin{array}{l}\text { Simulaton } \\
\text { Flow }\end{array}$ & $\begin{array}{l}\text { Average } \\
\text { deviation }\end{array}$ & $\begin{array}{l}\text { Maximum } \\
\text { deviation }\end{array}$ & $\begin{array}{l}\text { Minimum } \\
\text { deviation }\end{array}$ & & \\
\hline Ledu & 36.2 & 34.2 & $15.14 \%$ & $77.56 \%$ & $0.04 \%$ & 0.82 & 0.90 \\
\hline Minhe & 34.7 & 37.5 & $21.53 \%$ & $82.47 \%$ & $0.03 \%$ & 0.63 & 0.78 \\
\hline Honggu & 118.4 & 122.8 & $12.49 \%$ & $66.02 \%$ & $0.05 \%$ & 0.98 & 0.99 \\
\hline
\end{tabular}

2) water quality model.

The water quality classification and changing trend of main sections are nearly the same as measured. The relative errors of simulated value are all less than $10 \%$ which means that model parameter calibration fit the convergence criteria (Table.3).

Table 3. Main section fitting effects of model calibration parameters

\begin{tabular}{|c|c|c|c|c|c|c|}
\hline \multirow[b]{2}{*}{ section } & \multirow[b]{2}{*}{ index } & \multicolumn{4}{|c|}{ Measured value(mg/L) Simulation value(mg/L) } & \multirow{2}{*}{ Relative error } \\
\hline & & Average value $\mathrm{N}^{\mathrm{N}}$ & $\begin{array}{c}\text { Maximum } \\
\text { value }\end{array}$ & ${ }^{1}$ Average value & $\begin{array}{c}\text { Maximum } \\
\text { value }\end{array}$ & \\
\hline \multirow{2}{*}{ Xiaoxia Bridge } & COD & 26.9 & 32.0 & 27.4 & 32.6 & $4.32 \%$ \\
\hline & $\mathrm{NH}_{3}-\mathrm{N}$ & 3.9 & 5.8 & 4.0 & 6.0 & $4.42 \%$ \\
\hline \multirow{2}{*}{$\begin{array}{l}\text { Pingan } \\
\text { Bridge }\end{array}$} & COD & 27. & 31.9 & 25.7 & 28.6 & $4.41 \%$ \\
\hline & $\mathrm{NH}_{3}-\mathrm{N}$ & 4.0 & 5.5 & 4.1 & 5.8 & $6.62 \%$ \\
\hline \multirow{2}{*}{ Ledu } & COD & 25.7 & 28.6 & 26 & 32.3 & $3.85 \%$ \\
\hline & $\mathrm{NH}_{3}-\mathrm{N}$ & 3.5 & 5.3 & 3.6 & 5.2 & $9.00 \%$ \\
\hline \multirow{2}{*}{ Minhe } & COD & 22.3 & 28.4 & 22.9 & 33.6 & $9.40 \%$ \\
\hline & $\mathrm{NH}_{3}-\mathrm{N}$ & 2.7 & 3.6 & 2.6 & 3.4 & $8.30 \%$ \\
\hline
\end{tabular}

3) Model verification

We verified the model based on the daily observed data from September to December of 2013. The results show that the average errors of three main sections are all less than $20 \%$, the Nash efficiency index are $0.8,0.61$ and 0.94 for each section. The projected flow fitted errors, Nash efficiency indexes and relative coefficients of Ledu, Minhe and Honggu section all meet the parameter calibration criteria. The relative errors of four projected sections are all less than $10 \%$ in the water quality model's verification period which indicates that water volume and quality model's accuracy meet the criteria and process adaptability and reliability.

\section{Result Analysis}

\section{boundary conditions input}

Regular emission mode. Assume that domestic sewerage of cities in Huangshui River's watershed could all get efficient treatment, the reclaimed water reused ratio is larger than $30 \%$, circular economy development enterprises in Xining's Economic-Technological Development Area could get zero pollution, other industrial point pollution sources pollute steadily and meet the criteria. Based on those assumptions, we predict the main pollutions' inflow volume.

Pollutant cap control. To realize the aim of water function zones' water quality, Huangshui River's watershed should push stricter water resource management on basis of Chinese city sewerage concentration treatment, reclamation, up-to-standard emission and reclaimed economy. If the predicted inflow volume is less than assimilative ability, then we assume the predicted inflow volume 
as controlled inflow quantity. Otherwise, we assume the assimilative ability as controlled inflow quantity. The predicted main inflow pollution of two emission patterns in 2030 (Table.4).

Table 4. Forecast results of major pollutants entering the river in the pianning level years

\begin{tabular}{clccc}
\hline & \multicolumn{2}{c}{ Regular emission mode. } & \multicolumn{2}{c}{ Pollutant cap control. } \\
\cline { 2 - 5 } Partition area & COD & NH$_{3}-\mathrm{N}$ & COD & NH $_{3}-\mathrm{N}$ \\
\hline Heyuan-Shiyazhuang & 276 & 36 & 67 & 2 \\
Shiyazhuang-Xiaoxia & 5245 & 677 & 3503 & 202 \\
Beichuan River & 1890 & 271 & 593 & 25 \\
Xiaoxia-Minhe & 1996 & 274 & 1393 & 135 \\
Minhe-Yellow River & 2267 & 326 & 1086 & 11 \\
total & 11674 & 1584 & 6641 & 375 \\
\hline
\end{tabular}

\section{Water quality prediction}

Regular emission mode. As predicted, the COD concentrations could all meet the water function zone's water quality requirement in each section of Huangshui River from May to Oct. However, there exists different degree exceeded pollution and ammonia-nitrogen exceeds the standard during the whole year because of the dense cities pollution emission in Xining, Pingan, Ledu, Huzhu, Minhe, Honggu and the deficiency of pollution assimilative ability.

Pollutant cap control mode. Under the condition of average inflow, the $\mathrm{COD}$ and $\mathrm{NH}_{3}-\mathrm{N}$ of all sections in Xining in 2030 can meet the Grade IV water quality standard for surface water environment and meet the water quality target requirements in the water functional area.

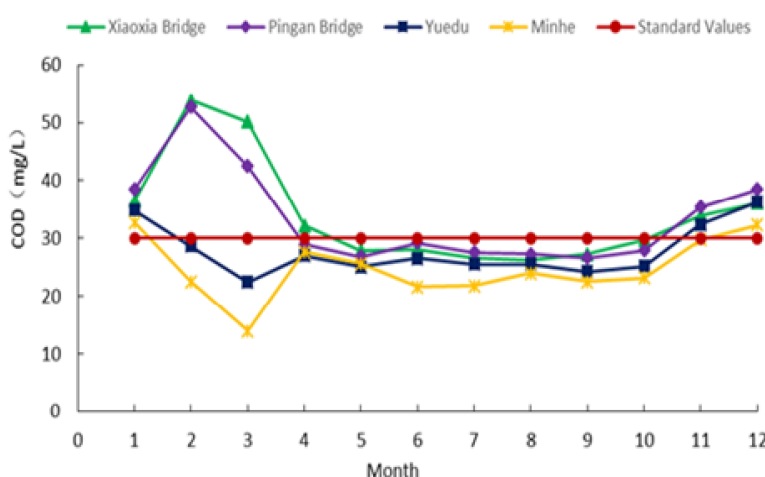

Figure 2. Comparison of COD Concentration Prediction and Standards for Each Section of Huangshui River Main stream in 2030. (Regular emission mode)

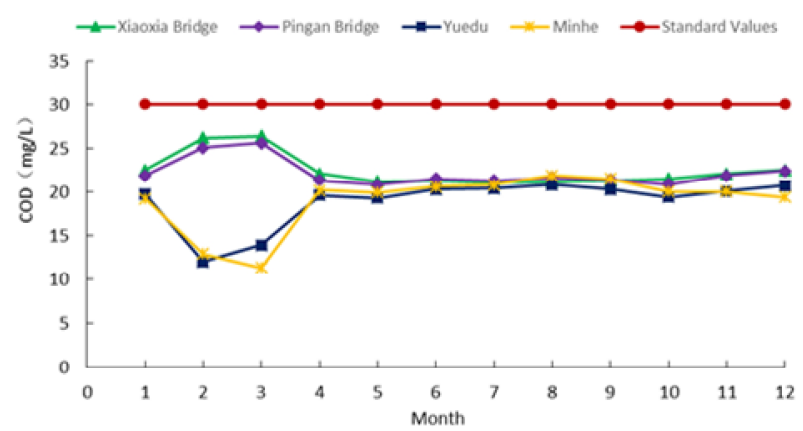

Figure 4. Comparison of COD Concentration prediction and Standards for Each Section of Huangshui River Main stream in 2030. (Pollutant cap control mode)

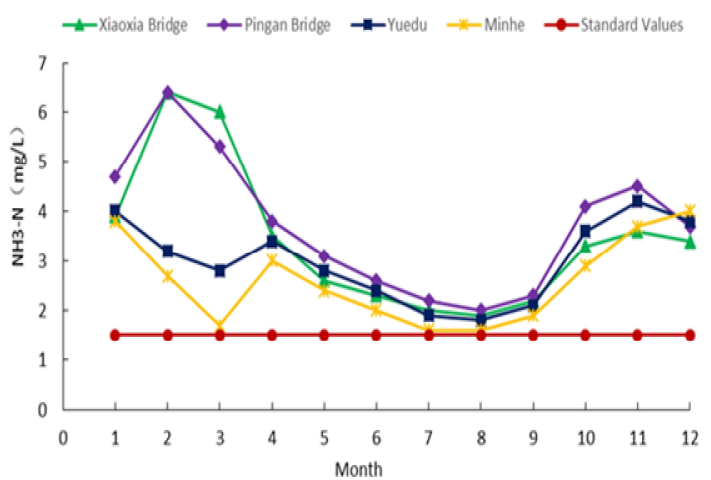

Figure3. Comparison of $\mathrm{NH}_{3}-\mathrm{N}$ Concentration Prediction and Standards for Each Section of Huangshui River Main stream in 2030. (Regular emission mode)

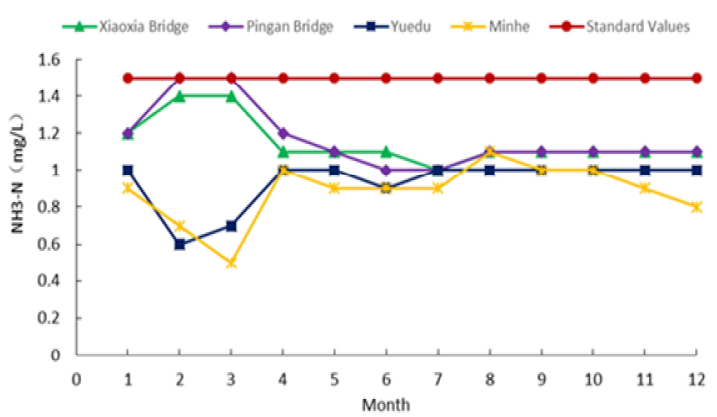

Figure 5. Comparison of $\mathrm{NH}_{3}-\mathrm{N}$ Concentration prediction and Standards for Each Section of Huangshui River Main stream in 2030 (Pollutant cap control mode)

\section{Effectiveness analysis}

Based on the comprehensive scenarios analysis, under regular emission mode, the dense pollution emission of Xining downstream would cause the COD exceeding standard during dry season and $\mathrm{NH}_{3}-\mathrm{N}$ exceeding during the whole year in the sections of Xining, Pingan, Ledu, Huzhu, Minhe and 
so on. Under pollutant cap control mode, more than 95\% domestic sewerage in the watershed could get effective treatment and outflow steadily meet the one-class A permitted criteria, reclaimed water re-used ratios are improved to more than $50 \%$. Also, the $\mathrm{COD}$ and $\mathrm{NH}_{3}-\mathrm{N}$ of all Xining downstream sections could satisfy Surface water environment quality IV water quality standards and the water function zones' requirement. Therefore, compared with regular emission mode, the pollutant cap control mode has obvious emission reduction effectiveness and is an essential method to improve water quality.

\section{Conclusion}

Based on Huangshui River downstream below Xining as example, we built an one dimensional water quality and volume model by using MIKE11 and analysis the effectiveness of the main pollution reduction in Huangshui River watershed. The research shows that: 1). MIKE11 could simulate the sections' water quality and volume excellently, the three main sections' water volume average errors are less than $20 \%$ in verification and calibration periods, the simulated water quality average errors could be controlled under $10 \%$ which indicates that the model perform well and has high adaptability and reliability. 2). Pollutant cap control mode has better pollution reduction performance than regular emission mode. Under this scenario, the COD and $\mathrm{NH}_{3}-\mathrm{N}$ of all Xining downstream sections could satisfy Surface water environment quality IV water quality standards and the water function zones' requirement. Therefore, the pollutant cap control mode is an essential method to improve water quality.

In this research, we only select the inflow pollution volume after pollutant cap control as data sources to simulate the result of water quality improving in control section. Also, we analyze the effectiveness of the sewage interception, improving sewage treatment works' criteria, river water quality improvement and other methods to get the best water treatment methods assembly.

\section{Acknowledgements}

This work was financially supported by The National Key Research and Development Program of China (2017YFC0404406 and 2017YFC0404401).

\section{References}

[1] Arega F, Sanders B F. Dispersion model: Tidal wetlands. Journal of Hydraulic Research, 130 (8):739-754. (2003)

[2] Danish Hydraulic Institute (DHI) system for rivers and channels MIKE11: a modelling reference manual. Copenhagen: DHI. (2007)

[3] Jin C J, Wang C, Fan X N, et a1. The application of water quality model of Songhua River mainstream in basin water resources protection and management. Journal of Hydraulic Engineering, 39(1) :86-92. (2010)

[4] Kotti M E, Vlessidis A G, Thanasoulias N C, Evmiridis N P. Assessment of river water quality in Northwestern Greece. Water Resour Manag 19(1):77-94. (2005)

[5] Lin G Q, Zhang Y R, Sun Y G, et a1. Optimal design of wetland ecological water in the Shuangtaizi Estuarv, Panjin. Procedia Environmental Sciences, 12: 1404-1410. (2012)

[6] Wang Q G, Zhao X H, Wu W J, et al. Advection-diffusion models establishment of water-pollution accident in middle and lower reaches of Hanjiang River. Advances in Water Science, 19(4): 500-504. (2008) 
[7] Xiong H B, Zhang S S, Kuang W, et al. Control measure efficiency analysis of estuarine water pollution sources based on MIKE11 model. Acta Scientiae Circumstantiae, 37(4):1573-1581. (2017) 